\begin{tabular}{|l|l|l||}
\hline \multicolumn{2}{|c|}{ PublisherInfo } \\
\hline \hline PublisherName & $:$ & BioMed Central \\
\hline \hline PublisherLocation & $:$ & London \\
\hline \hline PublisherImprintName & $:$ & BioMed Central \\
\hline \hline
\end{tabular}

\title{
A novel regulator of Th1 differentiation
}

\begin{tabular}{||l|l|l||}
\hline \multicolumn{2}{|c||}{ ArticleInfo } \\
\hline \hline ArticleID & $:$ & 187 \\
\hline \hline ArticleDOI & $:$ & $10.1186 /$ ar-2000-66804 \\
\hline \hline ArticleCitationID & $:$ & 66804 \\
\hline \hline ArticleSequenceNumber & $:$ & 144 \\
\hline \hline ArticleCategory & $:$ & Paper Report \\
\hline ArticleFirstPage & $:$ & 1 \\
\hline \hline ArticleLastPage & $:$ & 4 \\
\hline \hline & $:$ & RegistrationDate : 2000-5-2 \\
ArticleHistory & $:$ & OnlineDate \\
\hline \hline ArticleCopyright $2000-5-2$ \\
\hline \hline ArticleGrants & $:$ & Current Science Ltd2000 \\
\hline \hline ArticleContext & $:$ & \\
\hline \hline
\end{tabular}


Aff1 Kennedy Institute of Rheumatology, UK

\title{
Keywords
}

\author{
Differentiation, IFN-?, thymocyte, transcription
}

\section{Context}

T helper (Th) lymphocytes differentiate into distinct (Th1 and Th2) subsets, which can be distinguished on the basis of their profiles of cytokine secretion. Th1 and Th2 cells differ in function, and play different roles in T-cell-mediated pathophysiological processes. Th2 differentiation is reasonably well understood, and several transcription factors (TFs) have been implicated, including cMaf, NFAT, GATA-3 and Stat6. In contrast Th1 differentiation is poorly understood. Whilst TFs such as Stat4, IRF-1 and ERM have been implicated, these are not thought to play primary roles in the specification of the Th1 differentiation pathway. To identify TFs involved in the Th1 differentiation pathway.

\section{Significant findings}

IL-2-promoter-binding factors were identified from a Th1 cDNA library by yeast one-hybrid screen. Positive clones were confirmed as Th1-specific by hybridisation with a radiolabelled Th1, but not an equivalent Th2 cDNA pool. Eight clones which were positive in both screens encoded a novel TF belonging to the 'T box' family, named T-bet. T-bet was expressed in Th1 cell lines and upregulated by stimulation with anti-CD3, or with PMA/ionomycin. T-bet was expressed early during differentiation of naive primary $\mathrm{T}$ cells in vitro to Th1 cells. The following observations implicated T-bet as a positive regulator of the Th1 marker gene IFN-?. Expression of T-bet coincided with the induction of IFN? in B and NK cells. Overexpressed T-bet activated an IFN-?-luciferase reporter construct, but negatively regulated an IL-2 luciferase reporter. Finally, T-bet activated expression of the endogenous IFN-? gene in transiently transfected EL4 cells and retrovirally transduced primary $\mathrm{CD} 4^{+}$cells. Further experiments suggested that $\mathrm{T}$-bet can direct Th1 differentiation. Naive $\mathrm{T}$ cells were infected with T-bet retrovirus and maintained in Th2-inducing conditions for 7 days, after which the virally transduced cells significantly overexpressed IFN-? and underexpressed IL-4 when compared to controls. Strikingly, if retroviral infection was performed after 9, 21 or 28 days of Th2-inducing culture, T-bet was able to redirect "terminally differentiated" Th2 effector cells into the Th1 pathway, upregulating IFN-? and downregulating both IL-4 and IL-5. This downregulation of expression was also seen in a stable Th2 
cell line. Negative regulation of IL-4 and IL-5 expression occurred in T cells lacking the IFN-? receptor, and thus was not secondary to IFN-? production.

\section{Comments}

This exceptional and detailed paper provides many novel insights into the process of lineage commitment in the immune system, a phenomenon which is of clear relevance to autoimmune disease. It is convincingly demonstrated that $\mathrm{T}$-bet ( $\mathrm{T}$ box expressed in $\mathrm{T}$ cells) plays a central role in commitment to the Th1 pathway under various conditions of $\mathrm{T}$ cell stimulation. The effects of $\mathrm{T}$-bet expression in $\mathrm{T}$ cells or cell lines are somewhat dependent upon context. For example, the expression of interleukin 5 (IL-5) is invariably downregulated by T-bet; however, IL-4 expression is less strongly affected in some experiments. Interferon? (IFN-?) is induced by T-bet in most instances, but only weakly in a Th2 cell line. The interaction between T-bet and the IL-2 locus is also puzzling. Both T-bet and IL-2 are expressed early in Th1 differentiation; however, T-bet appears to repress the IL-2 gene. Much work will be required to understand the mechanism(s) of action of T-bet, and a T-bet knockout mouse would clearly be interesting.

\section{Methods}

A yeast one-hybrid screen of a Th1 cDNA library was performed, using part of the IL-2 promoter as 'bait'. This type of screen is used to isolate TFs on the basis of their interaction with the bait sequence, but provides no information about the functional properties of the factors isolated. A secondary screen employed pools of Th1- or Th2-specific radiolabelled cDNA. Expression of T-bet mRNA and protein was examined by northern and western blotting or by FACS analysis in a variety of haematopoetic cells and tissues. In some experiments naive T cells were driven to differentiate by culture with IL-12 and anti-IL-4 (Th1-inducing), or with IL-4, anti-IFN-? and anti-IL-12 (Th2-inducing). Effects of T-bet upon IL-2, IL-4 and IFN-? expression were assessed by co-expression with appropriate luciferase reporter constructs in EL4 cells. Remaining experiments used retroviral vectors designed to express either green fluorescent protein (GFP) alone, or both GFP and T-bet. Retrovirally transduced T cells were FACSanalysed for the expression of various cytokines.

\section{References}

1. Szabo SJ, Kim ST, Costa GL, Zhang X, Fathman CG, Glimcher LH: A novel transcription factor, Tbet, directs Th1 lineage commitment. Cell. 2000, 100: 655-669.

This PDF file was created after publication. 